\title{
Valorizing recycled paper sludge by a bioethanol production process with cellulase recycling
}

\author{
Daniel Gomes, Lucília Domingues*, Miguel Gama \\ Centre of Biological Engineering - University of Minho, Campus de Gualtar - 4710-057 Braga, Portugal
}

\section{H I G H L I G H T S}

- The recycling of cellulases on the hydrolysis of recycled paper sludge was assessed.

- Cellulases and yeast cells showed good performances towards the substrate.

- Both cellulase fractions were shown to be easily recovered with good efficiencies.

- The hydrolysis of RPS was successfully conducted over 4 cycles.

- Cellulase recycling enabled enzyme savings between 53 and $60 \%$.

\section{A R T I C L E I N F O}

\section{Article history:}

Received 19 April 2016

Received in revised form 31 May 2016

Accepted 1 June 2016

Available online 2 June 2016

\section{Keywords:}

Recycled paper sludge

Cellulase recycling

Ultrafiltration

Alkaline wash

Cellulosic bioethanol

\begin{abstract}
A B S T R A C T
The feasibility of cellulase recycling in the scope of bioethanol production from recycled paper sludge (RPS), an inexpensive byproduct with around $39 \%$ of carbohydrates, is analyzed. RPS was easily converted and fermented by enzymes and cells, respectively. Final enzyme partition between solid and liquid phases was investigated, the solid-bound enzymes being efficiently recovered by alkaline washing. RPS hydrolysis and fermentation was conducted over four rounds, recycling the cellulases present in both fractions. A great overall enzyme stability was observed: 71,64 and $100 \%$ of the initial Cel7A, Cel7B and $\beta$-glucosidase activities, respectively, were recovered. Even with only $30 \%$ of fresh enzymes added on the subsequent rounds, solid conversions of 92,83 and $71 \%$ were achieved for the round 2,3 and 4 , respectively. This strategy enabled an enzyme saving around $53-60 \%$, while can equally contribute to a $40 \%$ reduction in RPS disposal costs.
\end{abstract}

(c) 2016 Elsevier Ltd. All rights reserved.

\section{Introduction}

The economic feasibility of second-generation bioethanol relies on two major cost factors: the substrate and the enzymes. The identification of a cheaper, abundant and easily hydrolysable material has assumed a critical role for a more economic production of fermentable sugars. Recently, an increased utilization of different kinds of residues came as an interesting alternative to the traditional lignocellulosic substrates, enabling a considerable reduction on substrate cost, and also an additional valorization for some of these otherwise useless materials.

Recycled paper sludge (RPS) is a residue originated from the paper recycling process, more specifically, from the treatment of the liquid effluents generated in that process. It is mostly composed of small fibers with approximately $40 \%$ of carbohydrates that

\footnotetext{
* Corresponding author.

E-mail address: luciliad@deb.uminho.pt (L. Domingues).
}

cannot anymore be incorporated on recycled paper (Marques et al., 2008a). Also, due to the chemical contamination, namely with ink particles, this residue has high environmental impact being usually disposed on landfills, which represents a considerable expenditure for these companies. Considering an approximate production of this waste around $300 \mathrm{~kg}$ per ton of recycled paper (Balwaik and Raut, 2011) and taking into account an estimated 47 millions tons of recycled paper produced only in Europe by the year of 2005 (Monte et al., 2009), this corresponds to around 14 million tons of RPS that need to be discarded. In spite of the notable potential of this material, coupled with a high worldwide availability, only few studies have been conducted so far exploring its further valorization (Presetyo and Park, 2013). Some examples refer to Lark et al. (1997) who have studied RPS hydrolysis and subsequent fermentation to ethanol by Kluyveromyces marxianus. Also Marques et al. studied its potential for bio-ethanol production by Pichia stipitis (Marques et al., 2008a) and lactic acid production by Lactobacillus rhamnosus ATCC 7469 (Marques et al., 2008b). 
In addition to the substrate cost, the cost of the enzymes required to hydrolyze lignocellulosic materials (cellulases and/or hemicellulases) represents one of the biggest obstacles for their economically viable conversion, due the competition from the less expensive fossil fuels. Great debate has been established concerning the exact cost of cellulases, with distinct values being pointed out by different authors. Klein-Marcusschamer et al. (2012) estimated a cost on ethanol production around $\$ 0.68$ per gallon, close to $\$ 0.5$ per gallon recently suggested by Novozymes (http:// novozymes.com/en/news/news-archive/Pages/45713.aspx). However, Aden and Foust (2009) have also already reported a value around \$ 0.1 per gallon, close to $\$ 0.3$ reported by Lynd et al. (2008) and \$ 0.32 reported by Dutta et al. (2010). Independently of the exact figure, it is consensually recognized that the enzymes cost is a major determinant of the cellulosic ethanol competitiveness, driving in the last years intense efforts to reduce the loading employed in the process. The reduction of the cost associated to enzymes has been commonly pursued following three main strategies: increasing the efficiency of enzymes; reducing enzymes production cost; and reutilizing the enzymes (Pribowo et al., 2012). Over the last years (even decades), most of the attention has been given to the first two strategies, through intense and constant research operated by both industry (e.g. Novozymes; DSM; Genencor) and academia. Through a close collaboration with Novozymes and Genencor, NREL (USA) conducted a joint project that resulted in a reduction of cellulase cost up to 10-fold (http://www. nrel.gov/docs/fy13osti/59013.pdf). Nevertheless, some authors have already admitted that such strategies will not allow pushing down cellulases cost much further. In this context, the recovery (and posterior reutilization) of cellulases has recently emerged as a very promising concept, as using enzymes multiple times will allow a natural reduction on its consumption.

Numerous studies have been conducted for some years now in what concerns the mechanisms of enzyme adsorption/desorption (Lindedam et al., 2013; Pribowo et al., 2012; Rodrigues et al., 2014; Tu et al., 2007), addressing the complexity associated to different enzymes and substrates. In a similar way, possible strategies to facilitate and/or conduct the recovery of these enzymes have already been individually studied. According to Gomes et al. (2015), enzymes remaining in the liquid fraction are usually recovered either by ultrafiltration or by addition to fresh substrate (and posterior separation), while solid-bound enzymes normally require a change of $\mathrm{pH}$ or the addition of specific chemical compounds (that interfere with solid-enzyme interaction). Nevertheless, very few studies were conducted so far presenting an integrated approach of such strategies to the hydrolysis of a specific lignocellulosic material over multiple rounds.

Here we conduct an overall study regarding the feasibility of using RPS as substrate for 2G-bioethanol production in a system of multiple rounds of hydrolysis with cellulase recycling. The conservation of enzymatic activity and its final partition between solid and liquid fractions is initially accessed followed by an evaluation regarding the recovery efficiency of solid-bound enzymes. Afterwards, a process with multiple rounds of hydrolysis and enzymes recycling was implemented, monitoring the activity levels and the degree of solids conversion over the entire process.

\section{Material and methods}

\subsection{Enzymes and substrate}

Enzymatic hydrolysis were conducted through the combined action of the commercial cocktail Celluclast (Sigma-Aldrich, C2730), complemented with the commercial $\beta$-glucosidase preparation Novozyme 188 (Novozymes). The activities of these preparations were determined to be $45 \mathrm{FPU} / \mathrm{mL}$ and $611 \mathrm{IU} / \mathrm{mL}$, respectively.

The recycled paper sludge (RPS) was kindly provided by RENOVA (Torres Novas, Portugal). This refers to a solid (with approx. 53\% (w/v) water) obtained from the wastewater treatment of paper recycling effluents generated by this company. This material contains high carbonates content, which results on an alkaline solid. Similarly to Marques et al. (2008a), prior to its utilization RPS material was treated with hydrochloric acid 37\% and then washed, first with water and then with buffer $(0.1 \mathrm{M}$ acetic acid/sodium acetate). This process rendered a neutralized RPS (nRPS), which was used in all tests of the current work.

\subsection{Hydrolysis and fermentation}

Enzymatic hydrolysis of $n$ RPS material were conducted under a standardized system with variable times and temperatures according to the purpose of each study. After RPS neutralization (and washing), the wet neutralized solid (with approx. 85\% (w/v) water) was resuspended in $0.1 \mathrm{M}$ acetic acid/sodium acetate buffer $(\mathrm{pH}$ 4.8 ) to a consistency of $5 \%(w / v)$ (dry weight basis). After sterilization and cooling to room temperature, enzymes were added on a small volume of the abovementioned buffer, being filtersterilized (sterile Polyethersulfone (PES) syringe filters; $0.22 \mu \mathrm{m}$ ) into the mixture of solids. Unless otherwise stated, enzymes were added in a dosage of $20 \mathrm{FPU} / \mathrm{g}$ cellulose of Celluclast and with a $\beta$-glucosidase/Celluclast activity ratio of 5 . This ratio was defined aiming to attenuate any limitation of $\beta$-glucosidase activity in order to ensure that cellulase action would be the limiting element. Solid suspension was then incubated at $200 \mathrm{rpm}$ on an orbital shaker at variable times and temperatures $\left(35 / 50^{\circ} \mathrm{C}\right)$.

When a further fermentation was conducted, this mixture was inoculated with cells of Saccharomyces cerevisiae PE-2 strain (Basso et al., 2008; Pereira et al., 2014; collected on the beginning of the stationary phase) and the temperature reduced to $30^{\circ} \mathrm{C}$. After harvested from the culture medium, yeast cells were resuspended on ice-cold $0.9 \%(\mathrm{w} / \mathrm{v}) \mathrm{NaCl}$ and then added to the solids suspension in a ration of $8 \mathrm{~g} / \mathrm{L}$ (fresh biomass). Periodic sampling was conducted accordingly with the purpose of each study. A minimum of 2 independent replicates was always conducted for every test of this work.

\subsection{Recovery of solid-bound enzymes}

Enzymes adsorbed to the solid were recovered by a process of alkaline elution, as described previously by Rodrigues et al. (2012, 2014). Briefly, the final hydrolysate was centrifuged for $15 \mathrm{~min}$ at $2710 \mathrm{~g}$, after which the supernatant was collected (discarded or stored). The harvested solid was resuspended on an equal volume of freshly prepared $0.1 \mathrm{M}$ Tris- $\mathrm{HCl}$ buffer ( $\mathrm{pH} 9-10)$ and mixed for $2 \mathrm{~h}$ on a turning wheel (Rotator SB3-Stuart) at room temperature. At the end, the solids mixture was once again centrifuged and the supernatant (containing the eluted enzymes) collected and stored accordingly (at $4^{\circ} \mathrm{C}$ ) for future use.

\subsection{Multiple rounds of hydrolysis with enzyme recycling}

Enzymatic hydrolysis in the context of cellulase recycling were conducted on a similar way comparatively to the single-round experiments. Some modifications were however introduced concerning the solid preparation as described below.

For the first round, hydrolysis was performed according to the common procedure employed so far. The solids suspension (5\% $(\mathrm{w} / \mathrm{v})$ ) was mixed with $20 \mathrm{FPU} / \mathrm{g}$ cellulose of Celluclast 
(complemented with $\beta$-glucosidase) and incubated for 48 or $72 \mathrm{~h}$ at $35^{\circ} \mathrm{C}$. Afterwards, this mixture was inoculated with yeast cells and incubated for $6 \mathrm{~h}$ at $30^{\circ} \mathrm{C}$.

At the end of the round, and after samples collection, final broth was centrifuged ( $2710 \mathrm{~g}$ for $15 \mathrm{~min}$ ) to separate liquid and solid fractions. Supernatant, containing free enzymes (in the liquid fraction), was filtered through a $0.2 \mu \mathrm{m}$ pore PES filter to remove major impurities, being posteriorly stored at $4{ }^{\circ} \mathrm{C}$ until further use. The solid was subjected to an alkaline wash, as previously described on this section, after which phases were once again separated. Similarly to the liquid phase, the elution liquid, containing the desorbed enzymes, was filtered to remove impurities and stored until further use. Prior to its storage the alkaline $\mathrm{pH}$ of this liquid was adjusted to the common operational $\mathrm{pH}(4.8)$ through the addition of $1 \mathrm{M}$ acetic acid/sodium acetate buffer ( $\mathrm{pH} 4.8$ ). Final solid was repeatedly washed with distilled water, oven dried (at $45^{\circ} \mathrm{C}$ ) until an estimated water content below $10 \%$, and finally stored until further use.

For cellulase recycling, both fractions (stored at $4{ }^{\circ} \mathrm{C}$ ) were mixed and concentrated using a tangential ultrafiltration system Pellicon XL membrane with a $10 \mathrm{kDa}$ cut-off PES membrane (Millipore, Billerica, MA, USA). The two fractions were initially concentrated by diafiltration and, at the end, adjusted to a final fixed volume. Considering the results of exploratory ultrafiltration tests, where the enzyme concentration on the final liquid seemed to significantly influence the level of activity loss, the final ultrafiltration volume was set on this case to the maximum value allowed, considering the amount of liquid on the sterilized solid. To enable a maximum final ultrafiltration volume, the fresh new solid was centrifuged in sterile conditions after the sterilization process, contrarily to its utilization in the entire suspension. For a new round of hydrolysis, the sterilized solid was resuspended and transferred to a new sterilized Erlenmeyer flask using the enzyme suspension obtained from the previous ultrafiltration procedure, posteriorly filter-sterilized with $0.2 \mu \mathrm{m}$ PES syringe filters. For each recycling stage, a portion of fresh enzymes was added to this suspension, corresponding to $20 / 30 \%$ of the original enzyme dosage. The new solids suspension was then subjected to the same conditions of hydrolysis and fermentation, as previously described.

This procedure was applied over a total of 4 rounds of hydrolysis and fermentation, as illustrated on Fig. 1.

\subsection{Analytical procedures}

\subsubsection{Sugars and ethanol quantification}

After thawing, aliquots from hydrolysis and fermentation experiments were diluted, filtered and then analyzed by HPLC (High-Performance Liquid Chromatography) for glucose and ethanol quantification. Samples were eluted on a Varian MetaCarb $87 \mathrm{H}$ column at $60{ }^{\circ} \mathrm{C}$, with $0.005 \mathrm{M} \mathrm{H}_{2} \mathrm{SO}_{4}$ at a flow rate of $0.7 \mathrm{ml} / \mathrm{min}$, and a refractive-index detector.

\subsubsection{Measurement of enzymatic activity}

Samples collected for quantification of enzymatic activity were stored at $4{ }^{\circ} \mathrm{C}$ until further utilization. Cel7A, Cel7B and $\beta$-glucosidase activities were quantified by fluorescence spectroscopy with slight differences according to the specific cellulolytic component, following a modified version of the protocol previously published by Bailey and Tähtiharju (2003). For Cel7A, Cel7B and $\beta$-glucosidase quantification, $400 \mu \mathrm{L}$ of a freshly prepared solution of $1 \mathrm{mM}$ 4-methylumbelliferyl-b-D-cellobioside (MUC, SigmaAldrich, M6018), 4-methylumbelliferyl-b-D-lactopyranoside (MULac, Sigma-Aldrich, M2405) and 4-methylumbelliferyl-b-Dglucopyranoside (MUGlc, Sigma-Aldrich, M3633), respectively, were mixed with $50 \mu \mathrm{L}$ of enzyme sample (properly diluted on buffer considering the range of the method) and then incubated for $15 \mathrm{~min}$ at $50^{\circ} \mathrm{C}$. After that, the reaction was stopped by the addition of $550 \mu \mathrm{L}$ of $1 \mathrm{M} \mathrm{Na}_{2} \mathrm{CO}_{3}$ and measured on a black bottom 96 -well UV fluorescence microplate using a Biotech Synergy HT Elisa plate reader. For Cel7B quantification, the addition of $50 \mu \mathrm{L}$ of a mixture containing $1 \mathrm{M}$ glucose and $50 \mathrm{mM}$ cellobiose is still required, in order to inhibit Cel7A and $\beta$-glucosidase activities. Cel7A, Cel7B and $\beta$-glucosidase act on their specific substrates releasing free 4methylumbelliferone (MU, Sigma-Aldrich, M1508), which results on a change of the fluorescence spectra that is quantified for an excitation and emission wavelengths of 360 and $460 \mathrm{~nm}$, respectively.

\subsubsection{Determination of solid composition}

The solids main composition, either corresponding to the initial material or after enzymatic hydrolysis, was determined by quantitative acid hydrolysis. After oven drying (at $45^{\circ} \mathrm{C}$ ) to a water content inferior to $10 \%$, approximately $0.5 \mathrm{~g}$ of solid was mixed with $5 \mathrm{ml}$ of $72 \%(\mathrm{w} / \mathrm{v}) \mathrm{H}_{2} \mathrm{SO}_{4}$ for $1 \mathrm{~h}$ at $30^{\circ} \mathrm{C}$. Afterwards, this mixture was subjected to a dilute hydrolysis by raising the volume to a total

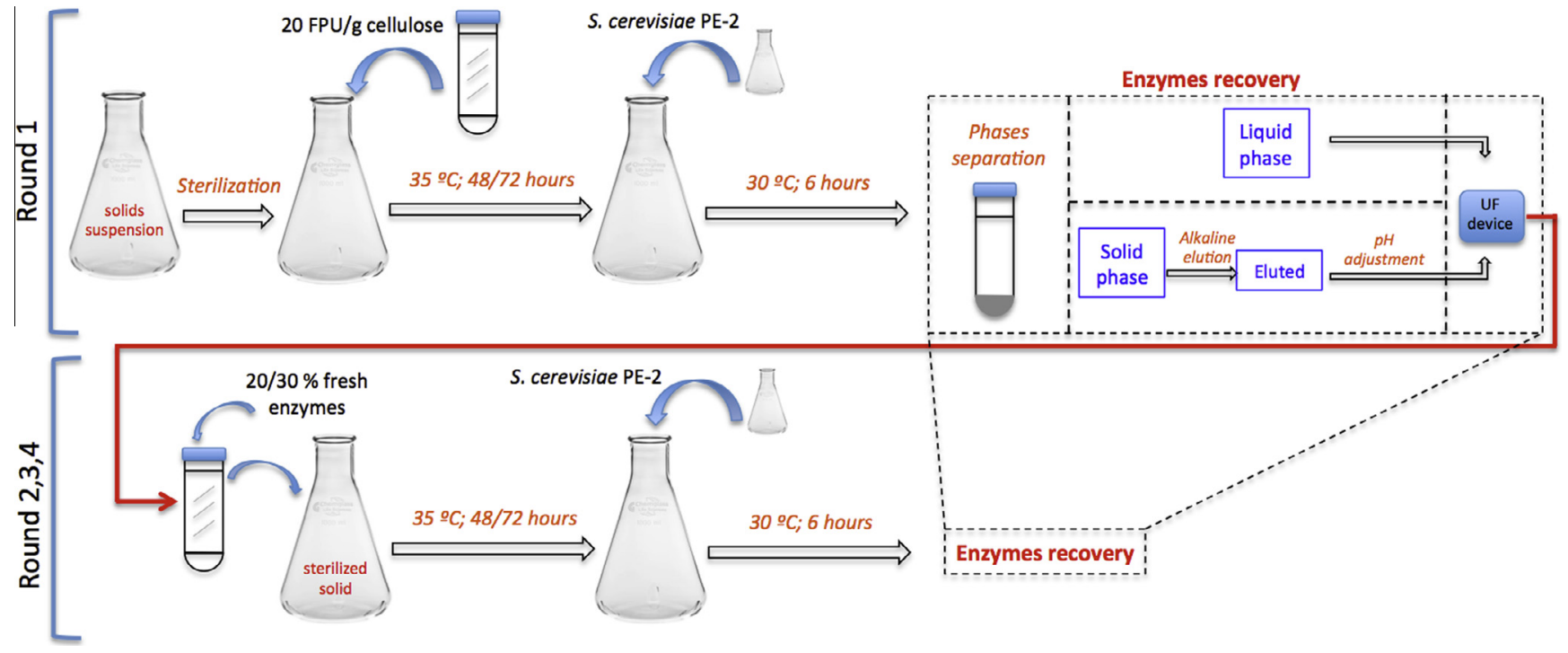

Fig. 1. Overall representation of the procedure for $n$ RPS hydrolysis during four consecutive rounds. 
mass of $148.67 \mathrm{~g}$ and posteriorly autoclavating for $1 \mathrm{~h}$ at $121^{\circ} \mathrm{C}$. After this, the solid residue was recovered by filtration (crisol Gooch $n^{\circ} 3$ ) and posterior drying (at $105^{\circ} \mathrm{C}$ ) until constant weight. Different sugar monomers formed during hydrolysis were quantified by HPLC analysis of the liquid fraction.

\section{Results and discussion}

\subsection{RPS composition on the main lignocellulosic components}

The feasibility of using $n$ RPS as substrate for 2G-bioethanol must be assessed. This depends on the presence of a meaningful amount of carbohydrates that can be later converted, and on its susceptibility to hydrolysis by cellulases.

As a residue derived from a production process that uses materials with some degree of heterogeneity (different types of paper residues), RPS composition is equally expected to present some variations from different production batches (Chen et al., 2014). Additionally, its composition may also vary depending on the specific context of its production as some variations on the paper residues used may be expected from one industry to another and also from different countries.

The $n$ RPS used in this work was kindly provided by RENOVA (Torres Novas, Portugal) and was initially analyzed for its main components. From this analysis, only $21 \%$ carbohydrates were estimated for this material, which makes it a relatively poor material as compared to most of the traditional lignocellulosic materials. Just to refer few examples, corncobs and wheat straw have approximately $80 \%$ of carbohydrates (Sun and Cheng, 2002). Considering the high carbonates content of this material, already reported by other authors (Marques et al., 2008a), a neutralization with hydrochloric acid was conducted for carbonates removal allowing to concentrate the carbohydrate fraction. As a matter of fact, cellulose content increased by around 2-fold to approximately $31 \%$ (w/w) and xylans to $7 \%$ (Table 1). A similar composition was reported by Marques et al. (2008a) for a RPS sample obtained from the same industry (RENOVA, Portugal). This is a more suitable composition considering its economic conversion to fermentable sugars.

\subsection{RPS digestibility and fermentation}

Considering that $n$ RPS is originated from the treatment of effluents with high amounts of contaminating chemicals, being inclusively associated to a considerable environmental impact (Park et al., 2001), it would be most relevant to investigate a possible toxicity effect over cellulases and cells, which would ultimately affect its conversion and fermentation. For that purpose, the profile of hydrolysis and posterior fermentation of a $5 \%(\mathrm{w} / \mathrm{v})$ solids suspension was investigated using a enzyme loading of $20 \mathrm{FPU} / \mathrm{g}$ cellulose (data not shown).

Table 1

Percentages of the main components in RPS composition.

\begin{tabular}{llll}
\hline & $\begin{array}{l}\text { Original } \\
\text { material }\end{array}$ & $\begin{array}{l}\text { After } \\
\text { neutralization }\end{array}$ & $\begin{array}{l}\text { Marques et al. } \\
(2008 \mathrm{a})\end{array}$ \\
\hline Cellulose & $16.25 \pm 0.36$ & $30.98 \pm 0.95$ & 34.1 \\
Xylan & $4.74 \pm 0.00$ & $7.02 \pm 0.19$ & 7.90 \\
Klason lignin & Not determined & Not determined & 20.4 \\
Ash & Not determined & Not determined & 29.3 \\
Protein & & & 4.80 \\
Fat & & & 3.50 \\
Acid-insoluble & $41.58 \pm 0.49$ & $62.55 \pm 1.87$ & $\begin{array}{l}\text { Not presented by } \\
\text { authors }\end{array}$ \\
\multicolumn{1}{c}{ solids } & & & \\
\hline
\end{tabular}

Glucose and ethanol profiles suggested that both cellulases and cells acted quickly and efficiently over the $n$ RPS material. After $48 \mathrm{~h}$ of hydrolysis approximately $92 \%$ of solid conversion was already achieved.

In what concerns glucose fermentation into ethanol, a fast conversion was equally achieved, being completed within a total of $6 \mathrm{~h}$. No indication of $n$ RPS toxicity was evident, yielding an ethanol productivity around $1.16 \mathrm{~g} / \mathrm{L} \mathrm{h}^{-1}$. Smaller values $\left(0.6 \mathrm{~g} / \mathrm{L} \mathrm{h}^{-1}\right)$ were obtained by Marques et al. (2008a) with Pichia stipitis, although using different conditions. This seems to support the high robustness and tolerance of PE-2 strain, as already reported by several reports (Gomes et al., 2012; Pereira et al., 2010, 2011, 2012, 2014). Additionally, further improvements may still be achieved in the current context with the possible utilization of MEC1121 strain (Romani et al., 2015), which resulted from the introduction of xylose fermentation pathway on the industrial robust $S$. cerevisiae PE-2 strain.

\subsection{Cellulase stability and final solid-liquid partition}

In the particular context of a cellulase recycling system, a specific set of factors gets special relevance. In addition to an effective substrate hydrolysis, cellulases must be stable enough as to allow multiple stages of hydrolysis, without compromising substrate conversion.

Besides a possible negative effect caused by the toxic nature of $n$ RPS, some other factors must also be accounted for, such as the temperature. Even though the optimal temperature of hydrolysis for fungal cellulases is commonly reported to be around $50^{\circ} \mathrm{C}$, an extensive exposure to this range of temperatures is usually associated to significant losses of activity (Chylenski et al., 2012; Rodrigues et al., 2014). For this reason, a system of multiple rounds of hydrolysis will require a careful choice of the temperature. The cellulase cocktail employed on this work was Celluclast, a widely used and studied commercial product from Novozymes, which has been reported to have great stability towards different environmental factors. In a previous study Rodrigues et al. (2012) accessed the thermal stability of Celluclast towards different possible operational temperatures. On a weeklong experiment the cellulase activity was not significantly affected in the range of $30-45^{\circ} \mathrm{C}$, while more than $50 \%$ of the activity was lost for a temperature of $50{ }^{\circ} \mathrm{C}$. Also, Chylenski et al. (2012) observed considerable increases on protein precipitation of $T$. reesei preparations for temperatures above $40^{\circ} \mathrm{C}$. To access possible toxicity effects from the substrate, a study was performed incubating $n$ RPS material with the cellulases at $35{ }^{\circ} \mathrm{C}$ (to avoid thermal denaturation), employing two distinct enzyme dosages (Fig. 2), and the loss of activity was monitored.

From the levels of Cel7A activity during the process (the most abundant cellulase component secreted by $T$. reesei and hence considered here as an indicator of overall cellulase activity) it was possible to observe that some loss of activity occurred, being more prominent for the lower enzyme dosage. Using $80 \mathrm{FPU} / \mathrm{g}$ cellulose, which is considerably high when compared to the traditional range of values employed on literature (10-40 FPU), approximately $6.8 \%$ of Cel7A activity was lost over the entire process (Fig. 2A). Most of this loss occurred on the first stage of the process, corresponding to a $48 \mathrm{~h}$ period of exclusive hydrolysis, and after which the activity seemed to stabilize with no significant changes during the additional $24 \mathrm{~h}$ of fermentation. As opposing to that, Cel7A activity decreased nearly $23.4 \%$ when a dosage of $20 \mathrm{FPU} / \mathrm{g}$ cellulose was applied, with $13.8 \%$ occurring on the first phase and the remaining $9.5 \%$ in the second one (Fig. 2B). It is most relevant to refer that in terms of absolute values, the activity losses were actually not very different ( 0.698 and $0.564 \mathrm{FPU} / \mathrm{g}$ cellulose, respectively), which somehow suggests that this loss of activity might be dependent 

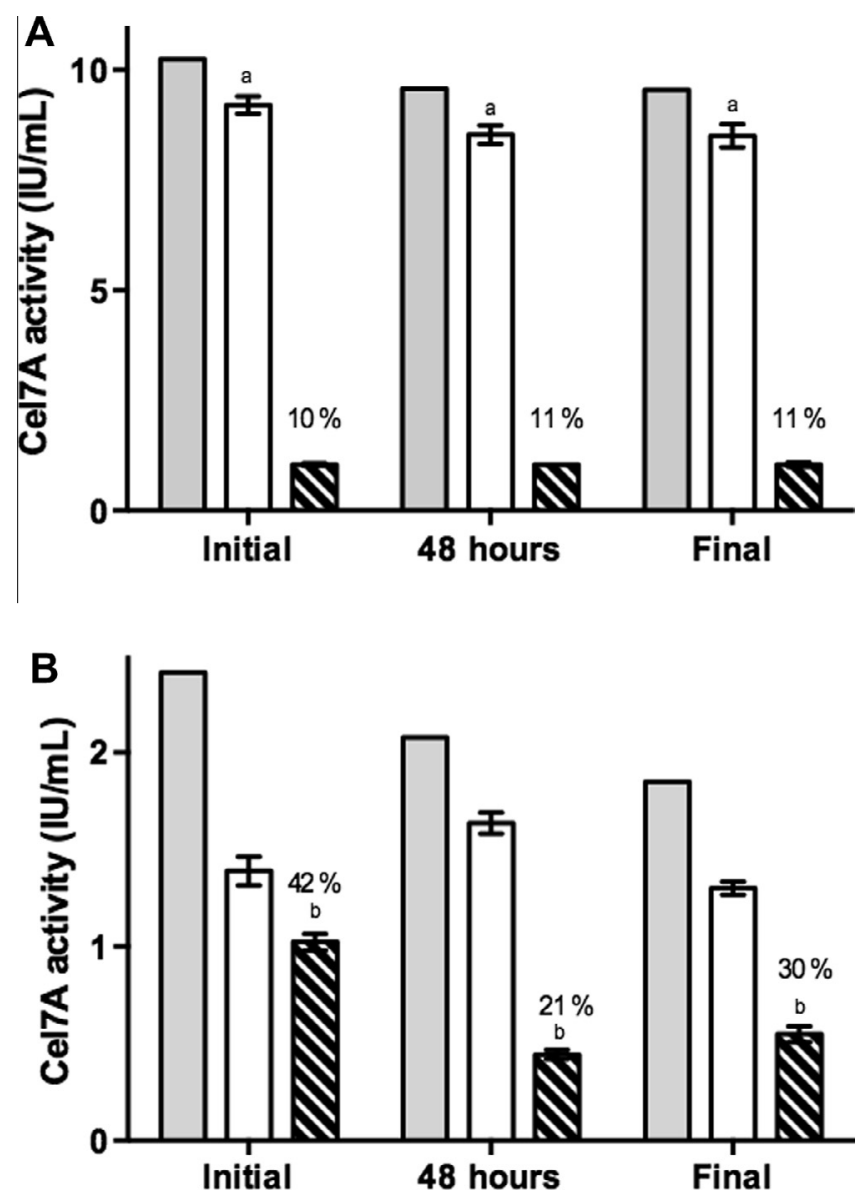

Fig. 2. Distribution of Cel7A activity between fractions (| | Total activity | | Liquid phase $\mathbb{N}$ Solid phase) over a process of SHF of $\boldsymbol{n R P S}$ : (A) using $80 \mathrm{FPU} / \mathrm{g}$ cellulose and (B) $20 \mathrm{FPU} / \mathrm{g}$ cellulose (percentages of the solid-bound enzymes are presented for the different stages of the process; yeast cells were added at $48 \mathrm{~h}$ of hydrolysis and fermentation occurred for additional $24 \mathrm{~h}$ ); (variation of enzyme activity was statistically different at a significant level of $95 \%$ (a) or $90 \%$ (b)).

on the amount of substrate (perhaps related to enzyme inactivation by adsorption to the solid).

In addition to the overall variation of activity during the process of hydrolysis, one other factor that may critically affect the efficiency of cellulase recycling refers to its distribution among the liquid and solid fractions (Gomes et al., 2015). This will strongly determine the strategies required for their recovery, and ultimately, the process efficiency.

Most of final Cel7A activity was present on the liquid fraction for both enzyme dosages, which is in agreement with the common mechanism of cellulose hydrolysis, after which enzymes are released to the liquid fraction. Similarly to what was observed for the activity loss, even though the fraction of cellulase activity adsorbed to the final solid was considerably higher at lower enzyme dosage (30\% for $20 \mathrm{FPU} / \mathrm{g}$ cellulose; $11 \%$ for $80 \mathrm{FPU} / \mathrm{g}$ cellulose), the amount of adsorbed activity in both cases $(1.045 \mathrm{IU} / \mathrm{mL}$; $0.548 \mathrm{IU} / \mathrm{mL}$ ) was not so different, suggesting as expected that enzyme adsorption relies on the substrate availability and its respective contact area. In this way, for a given amount of solid it seems to exist a maximum enzyme retention capability at the end of the process.

In what concerns the most realistic scenario, using $20 \mathrm{FPU} / \mathrm{g}$ cellulose, it is worth noting that despite most of the final activity being located in the liquid fraction, the amount that remained adsorbed to the solid was still relevant (30\%), which gets special significance in this context of cellulase recycling since it cannot be directly recovered, as occurs for the liquid fraction enzymes.

\subsection{Recovery of solid-bound cellulases}

The interaction of cellulases with lignocellulosic materials is a complex process. Not only different enzymes present distinct affinities for a specific solid (Ishihara et al., 1991; Pribowo et al., 2012), but also a specific enzyme seems to behave differently towards diverse materials (Tu et al., 2007). In a previous work Rodrigues et al. (2012) have clearly demonstrated that the final solid composition plays an essential role determining the efficiency of cellulase recovery, showing that Cel7A has apparently higher affinity for cellulose rather than lignin, hence being harder to recover when adsorbed to the former.

Aiming to clarify whether cellulases can be recovered from the solid fraction, an alkaline elution of the enzymes adsorbed on the solid residue was tested. Taking into account the levels of Cel7A activity over the entire process, one can observe that near $82 \%$ of the solid-bound enzymes were recovered to the elution liquid, and thus, can equally be reused on a new hydrolysis (Table 2). Furthermore, no significant loss of activity occurred as a result of the elution process, suggesting that this specific procedure, by which the solid with the adsorbed cellulases is incubated with Tris- $\mathrm{HCl}$ ( $\mathrm{pH} 9$ ), does not compromise the enzyme functionality. Employing similar strategies, equally based on a shift to alkaline $\mathrm{pH}$, similar results were reported on other studies. With a $\mathrm{pH}$ change from 8 to 13, Zhu et al. (2009) were able to desorb approximately $94 \%$ of the cellulases adsorbed on diluted acid pre-treated cornstover. More recently, Shang et al. (2014) were able to recover approximately $85 \%$ of cellulases adsorbed to corncob by increasing the $\mathrm{pH}$ to 10 .

\section{5. nRPS hydrolysis with cellulase recycling over multiple rounds}

The previous results gave promising indications regarding the possibility to recover cellulases after hydrolysis, to be later reused. Following these results it comes the question of whether a system developed to recover and reuse these enzymes can be applied without compromising the efficiency of solid conversion over the several rounds of hydrolysis.

To answer that question, four consecutive rounds of $n R P S$ hydrolysis and fermentation (SHF) were conducted, with enzyme recycling complemented with only $20 \%$ of fresh enzyme (4 FPU/g cellulose) added in the beginning of each new round. At the end of each round, enzymes (from both fractions) were recovered and separated from the final products (by ultra-filtration), and then mixed with fresh enzymes and incubated with fresh solid. The activities of three important cellulolytic components (Cel7A, Cel7B and $\beta$-glucosidase) were monitored to access possible variations during the entire process (Fig. 3).

From an overall analysis of Fig. 3, it seems clear that the variation on the activity levels for the different cellulase components presented some differences, mostly between the profiles of Cel7A and Cel7B, and the one of $\beta$-glucosidase.

As it was seen before, some of the Cel7A activity was lost during each round, which seemed to occur on a slightly higher degree for

Table 2

Cel7A recovery by alkaline elution of the nRPS hydrolysis residue.

\begin{tabular}{|c|c|c|}
\hline \multicolumn{2}{|c|}{ Enzyme activity } & $\begin{array}{l}\text { Cel7A activity (IU/ } \\
\mathrm{mL})\end{array}$ \\
\hline \multicolumn{2}{|c|}{ Solid-bound activity at the end of hydrolysis } & $0.789 \pm 0.014$ \\
\hline After alkaline & - total & $0.764 \pm 0.060$ \\
\hline \multirow[t]{3}{*}{ elution } & - in the supernatant & $0.646 \pm 0.035$ \\
\hline & - bound to the solid & $0.118 \pm 0.009$ \\
\hline & $\begin{array}{l}\text { Fraction recovered from the solid } \\
(\%)\end{array}$ & $81.8 \pm 4.71$ \\
\hline
\end{tabular}



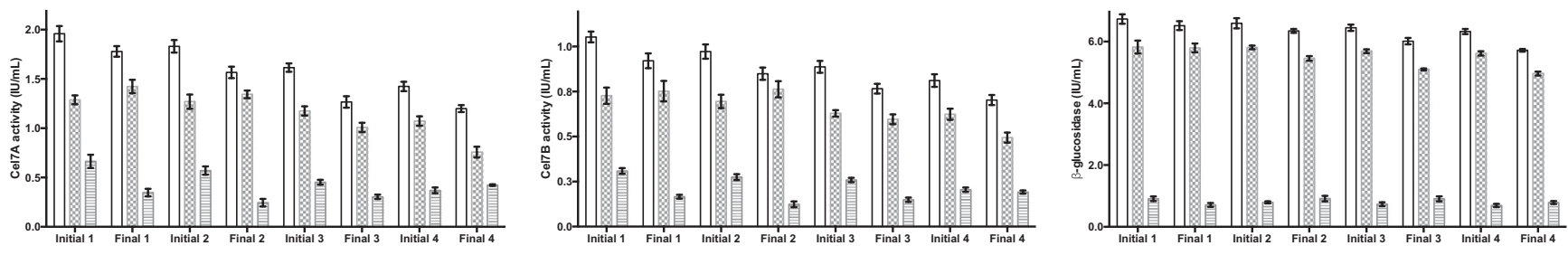

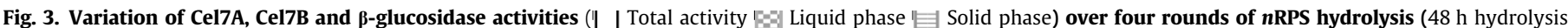

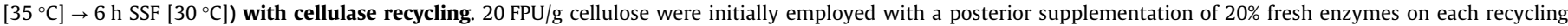
stage; total activity was statistically different over the distinct rounds at a significant level $(\mathrm{p}<0.05)$

Table 3

Multiple rounds of $n$ RPS hydrolysis ( $48 \mathrm{~h}$ hydrolysis $\left[35^{\circ} \mathrm{C}\right] \rightarrow 6 \mathrm{~h} \mathrm{SSF}\left[30^{\circ} \mathrm{C}\right]$ ) with cellulase recycling (20 FPU/g cellulose; $20 \%$ fresh enzymes).

\begin{tabular}{|c|c|c|c|c|}
\hline Round & Glucose $^{*}(\mathrm{~g} / \mathrm{L})^{\mathrm{a}}$ & Ethanol $(\mathrm{g} / \mathrm{L})^{\mathrm{b}}$ & Glucans in final solid (\%) $^{\mathrm{a}}$ & Glucans conversion (\%) \\
\hline 1 & $14.87 \pm 0.06$ & $7.06 \pm 0.07$ & $2.52 \pm 0.06$ & $91.88 \pm 0.21$ \\
\hline 2 (recycling 1 ) & $13.89 \pm 0.05$ & $6.21 \pm 0.36$ & $4.33 \pm 0.48$ & $86.02 \pm 1.55$ \\
\hline 3 (recycling 2) & $12.19 \pm 0.03$ & $5.69 \pm 0.04$ & $8.74 \pm 0.35$ & $71.79 \pm 1.14$ \\
\hline 4 (recycling 3 ) & $9.82 \pm 0.41$ & $4.63 \pm 0.08$ & $13.25 \pm 0.49$ & $57.23 \pm 1.60$ \\
\hline
\end{tabular}

* Before yeast inoculation.

a Differences between the values obtained in the distinct rounds are statistically significant $(\mathrm{p}<0.05)$.

b Differences between the values obtained in the distinct rounds are statistically significant $(\mathrm{p}<0.1)$.

the two last rounds. Nevertheless, approximately $61 \%$ of Cel7A activity was conserved over the four consecutive rounds of hydrolysis (and fermentation): the activity decreased from an initial $1.96 \mathrm{IU} / \mathrm{mL}$ (beginning of $1 \mathrm{st}$ round) to $1.20 \mathrm{IU} / \mathrm{mL}$. The supplementation of $20 \%$ of fresh cellulases (conducted on each recycling stage) was apparently not enough to fully compensate the losses occurred on each round. Apparently, a slightly superior supplementation of enzyme (25-30\%) would suffice to keep constant the initial levels of activity, leading to significant savings of enzyme. Exploratory tests previously conducted (results not shown) showed the occurrence of some loss of activity during the ultrafiltration process, which can change according to the range of the working enzyme dosage. Employing a similar enzyme recovery method (based on an ultrafiltration device, equipped with a $10 \mathrm{kDa}$ membrane), and the same cellulase preparation, Rodrigues et al. (2014) reported activity losses between 11 and $29 \%$.

In what concerns Cel7B activity, a similar behavior was observed. Total activity levels decreased from an initial $1.05 \mathrm{IU} /$ $\mathrm{mL}$ to $0.7 \mathrm{IU} / \mathrm{mL}$, which corresponds to an activity maintenance around $67 \%$. Once again, the supplementation of fresh enzyme enabled the satisfactory maintenance of activity along the different rounds, although not being sufficient to restore it completely. As for the case of Cel7A, the activity levels also suggested the occurrence of some enzyme loss during the steps of enzyme recovery and concentration.

The enzyme distribution between the solid residue and the supernatant occurred accordingly to what was observed previously. Most of Cel7A and Cel7B were free on the liquid fraction but a significant portion, ranging from 15 to $36 \%$ for Cel7A and $14-28 \%$ for Cel7B, remained adsorbed to the final solid, which somehow justifies our option to also recover solid-bound enzymes. Worth noting is that, for both Cel7A and Cel7B, a gradual increase could be observed for this parameter from the second to the last round. This seems to meet an equally visible reduction produced on solid conversion for each round, which will be discussed below (Table 3).

Differently from Cel7A (a cellobiohydrolase) and Cel7B (an endoglucanase), $\beta$-glucosidase presented a considerably distinct behavior. Even though a loss of activity also occurred on each round, these were observed to a much smaller extent comparatively to the other cases, resulting in a cellulase activity equivalent to $85 \%$ of the initial level after the four rounds of hydrolysis. In this case there was almost no variation on the levels of $\beta$-glucosidase activity adsorbed to the final solid over the different rounds (Fig. 3). In addition to that, the fraction of enzymes remaining adsorbed to the final solid were around $14 \%$, which is clearly inferior comparatively to the other enzymes. This suggests a lower solid-adsorption efficiency for these enzymes (Gomes et al., 2015; Ishihara et al., 1991; Lindedam et al., 2013), which is explained by the lack of a cellulose-binding module (CBM) in this class of enzymes.

Previous results suggested some heterogeneity in what concerns the stability and adsorption behavior of different cellulolytic components over the entire recycling experiment. Although providing important indications, the viability of this process is ultimately accessed based on how it allows high solid conversions. Glucans conversion decreased from 92\%, on the first round, to $57 \%$ in the last one (Table 3 ), probably translating the gradual decrease in the Cel7A and Cel7B activities from one round to another (Table 3). Still, it is worth noting that the decrease observed on glucans conversion appeared to occur on a higher rate comparatively to the depletion of enzymes activities. As example, while the relative decrease on glucans conversion was around 20.3\% from round 3 to round 4 , final Cel7A activity only decreased $5.3 \%$. A possible explanation may rely on the fact that the reported values of activity are associated to the utilization of specific substrates, which may not entirely simulate the hydrolysis of $n$ RPS material. As commonly known, the lignocellulosics hydrolysis relies on the simultaneous action of several enzymes, being therefore limited by the availability of all of these enzymes. It is possible that, even conserving the ability to act on the low-molecular weight substrates (MUC; MULAC), a small part of these enzyme's ability to bind and/or convert $n$ RPS material is lost during the several rounds of hydrolysis. Such fact inclusively supports the importance of adding some portion of fresh enzymes at the beginning of each new round, which can attenuate this effect.

Even with the abovementioned decreases on solid conversion, it should be referred that by using only $20 \%$ of fresh enzyme on the second round, $86 \%$ of glucans were converted, dropping to $72 \%$ on a third round. From a technical-economic overall analysis, considering a four-round system, this strategy enables a $60 \%$ saving on enzyme utilization. Process analysis should be carefully conducted 
Table 4

Multiple rounds of $n$ RPS hydrolysis $\left(72 \mathrm{~h}\right.$ hydrolysis $\left[35^{\circ} \mathrm{C}\right] \rightarrow 6 \mathrm{~h} \mathrm{SSF}\left[30^{\circ} \mathrm{C}\right]$ ) with cellulase recycling (20 FPU/g cellulose; $30 \%$ fresh enzymes).

\begin{tabular}{|c|c|c|c|c|}
\hline Round & Glucose $^{*}(\mathrm{~g} / \mathrm{L})^{\mathrm{a}}$ & Ethanol $(\mathrm{g} / \mathrm{L})^{\mathrm{a}}$ & Glucans in final solid (\%) & Glucans conversion (\%) \\
\hline 1 & $16.15 \pm 0.11$ & $7.70 \pm 0.02$ & $1.78 \pm 0.05$ & $94.27 \pm 0.16$ \\
\hline 2 (recycling 1 ) & $15.79 \pm 0.18$ & $7.59 \pm 0.06$ & $2.50 \pm 0.25$ & $91.95 \pm 0.80$ \\
\hline 3 (recycling 2) & $14.21 \pm 0.11$ & $6.63 \pm 0.03$ & $5.27 \pm 0.09$ & $83.01 \pm 0.30$ \\
\hline 4 (recycling 3 ) & $11.99 \pm 0.14$ & $5.65 \pm 0.08$ & $9.08 \pm 0.28$ & $70.69 \pm 0.91$ \\
\hline
\end{tabular}

* Before yeast inoculation.

a Differences between the values obtained in the distinct rounds are statistically significant $(\mathrm{p}<0.05)$.
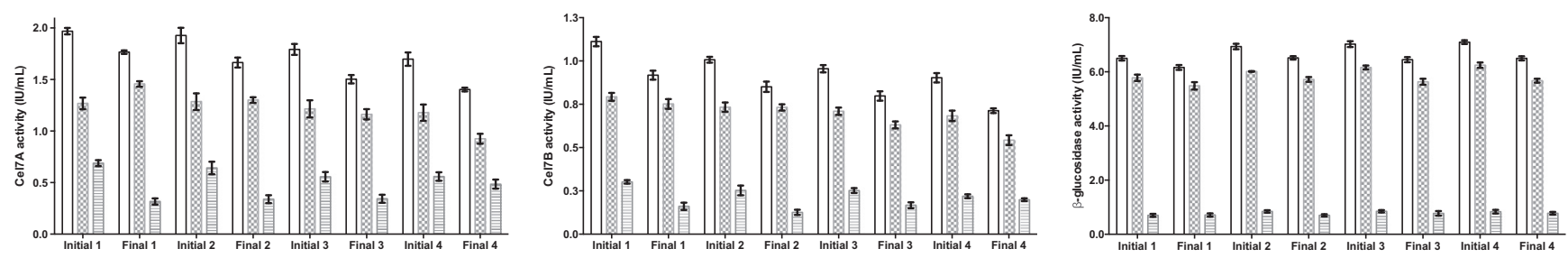

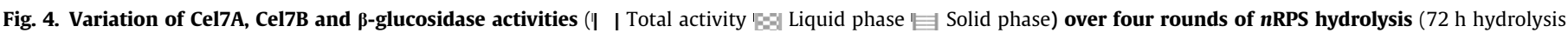

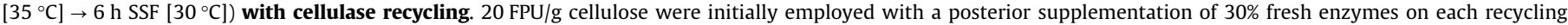
stage; total activity was statistically different over the distinct rounds at a significant level $(\mathrm{p}<0.05)$.

in this context, as a proper balance must be achieved considering the decrease on solid conversion and the costs of strategies aiming further improvements. On this specific case, we should consider that after a specific critical point, which we can assume as the end of round 2 , or ultimately the round 3 , the values of glucans conversion decreased to a level that compromise the overall viability of this process. In the scope of an optimization of this system, some strategies may be explored to surpass this limitation. Increasing the hydrolysis time or the supplementation of fresh enzyme may result on valuable improvements, as was observed on this work.

When the current study was conducted in similar conditions but with a hydrolysis time of $72 \mathrm{~h}$ and $30 \%$ fresh enzymes supplementation, considerable improvements were observed (Table 4; Fig. 4). Comparatively to the previous scenario, the depletion on solid conversion between rounds occurred considerably slower as $83 \%$ of glucans were still converted on round 3, opposing to $72 \%$ observed in the first case. For the last round, $71 \%$ of glucans were still converted, opposing to a prohibitive $57 \%$ achieved in the first case.

Similarly to what has been observed for glucans conversion, improvements were also detected in the activity profiles of the several cellulases (Fig. 4), ultimately supporting the previous findings. Although similar enzyme distributions among different fractions were obtained, considerable improvements were observed in terms of enzyme stability along the different rounds. Specifically for the cases of Cel7A and Cel7B, the addition of a higher amount of fresh enzyme allowed not only to compensate the losses occurred during enzyme recycling (also observed on the previous scenario) but also to slightly exceed the final values of the previous round (before recycling). As a result, approximately 71.2 and $64.1 \%$ of enzymatic activity was conserved over the four rounds for Cel7A and Cel7B, respectively. Higher improvements were even obtained for the case of $\beta$-glucosidase, as activity levels did not change over the entire process, although a small loss occurred during each round. For this particular component it was even possible to exceed the levels of enzymatic activity of the initial round, which together with previous findings could suggest that a lower amount of this enzyme can be initially employed.

Assuming that similar solid conversions are obtained in the different rounds, which may require some process adjustments (e.g. higher hydrolysis time), considerable savings on enzyme consumption can be expected through the implementation of this enzyme recycling system. In a four-rounds scenario, by decreasing the enzyme loading to only $30 \%$, a reduction of approximately $53 \%$ can be expected on enzymes consumption. When applied on an industrial scale, tremendous economic gains can be achieved. For an industrial facility with an estimated annual production of 30 million gallons per year (DuPont have recently opened a similar facility in Nevada, IA, USA), and assuming an enzyme cost of

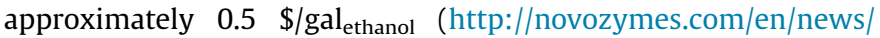
news-archive/Pages/45713.aspx), the application of the above described strategy would enable an approximate saving around $\$ 8$ million in enzymes. Several factors still need to be accounted for, such as the fact that enzymes can present a different cost (lower and higher values have been reported on the literature for this parameter) and that the recycling process also has a cost, but it seems very clear that, on a large scale production, this strategy of cellulase recycling can enable considerable economic gains. We should consider, however, that these results were obtained for the particular case of $n$ RPS material and different results may be expected for other materials. Therefore, this work shows first and mostly that $n$ RPS is a suitable material to be employed in the scope of cellulase recycling, although giving some indications that similar lignocellulosic materials may also be employed, after proper testing.

\section{Conclusions}

This study demonstrates the feasibility of cellulase recycling following hydrolysis/fermentation of RPS. This system may be highly interesting economically, as it exploits a substrate with significant costs of disposal. A strategy of cellulase recycling was efficiently applied over 4 rounds of hydrolysis. The addition of only $30 \%$ of fresh enzymes enabled an efficient conservation of activity levels and high solid conversions through the process. Additional improvements may still be achieved considering e.g. different times of hydrolysis or different fractions of fresh enzymes. Using this system, it was possible to reach enzyme savings in the range of $53-60 \%$. 


\section{Acknowledgements}

The authors acknowledge the financial support of the Portuguese Foundation for Science and Technology (FCT) under the scope of the strategic funding of UID/BIO/04469/2013 unit, COMPETE 2020 (POCI-01-0145-FEDER-006684) and the Project RECI/BBB-EBI/0179/2012 (FCOMP-01-0124-FEDER-027462). The financial support of FCT through GlycoCBMs Project PTDC/AGR-F OR/3090/2012-FCOMP-01-0124-FEDER-027948 and the PhD grant to DG (SFRH/BD/88623/2012) is equally acknowledged. The authors also thank RENOVA (Portugal) for kindly providing the recycled paper sludge.

\section{References}

Aden, A., Foust, T., 2009. Technoeconomic analysis of the dilute sulfuric acid and enzymatic hydrolysis process for the conversion of corn stover to ethanol. Cellulose 16, 535-545.

Bailey, M.J., Tähtiharju, J., 2003. Efficient cellulose production by Trichoderma reesei in continuous cultivation on lactose medium with a computer-controlled feeding strategy. Appl. Microbiol. Biotechnol. 62, 156-162.

Balwaik, S.A., Raut, S.P., 2011. Utilization of waste paper pulp by partial replacement of cement in concrete. Int. J. Eng. Res. Appl. 1, 300-309.

Basso, L.C., Amorim, H.V., Oliveira, A.J., Lopes, M.L., 2008. Yeast selection for fuel ethanol production in Brazil. FEMS Yeast Res. 8, 1155-1163.

Chen, H., Venditti, R., Gonzalez, R., Phillips, R., Jameel, H., Park, S., 2014. Economic evaluation of the conversion of industrial paper sludge to ethanol. Energy Econ. 44, 281-290.

Chylenski, P., Felby, C., Haven, M.Ø., Gama, M., Selig, M.J., 2012. Precipitation of Trichoderma reesei commercial cellulose preparations under standard enzymatic hydrolysis conditions for lignocelluloses. Biotechnol. Lett. 34, 1475-1482.

Dutta, A., Dowe, N., Ibsen, K.N., Schell, D.J., Aden, A., 2010. An economic comparison of different fermentation configurations to convert corn stover to ethanol using Z. mobilis and Saccharomyces. Biotechnol. Prog. 26, 64-72.

Gomes, D., Rodrigues, A.C., Domingues, L., Gama, F.M., 2015. Cellulase recycling in biorefineries: is it possible? Appl. Microbiol. Biotechnol. 99, 4131-4143.

Gomes, D.G., Guimarães, P.M.R., Pereira, F.B., Teixeira, J.A., Domingues, L., 2012. Plasmid-mediate transfer of FLO1 into industrial Saccharomyces cerevisiae PE-2 strain creates a strain useful for repeat-batch fermentations involving flocculation-sedimentation. Bioresour. Technol. 108, 162-168.

Ishihara, M., Uemura, S., Hayashi, N., Jellison, J., Shimizu, K., 1991. Adsorption and desorption of cellulase components during enzymatic hydrolysis of steamed shirakamba (Betula platyphylla Skatchev) wood. J. Ferment. Bioeng. 72, 96-100.

Klein-Marcusschamer, D., Oleskowicz-Popiel, P., Simmons, B.A., Blanch, W.H., 2012. The challenge of enzyme cost in the production of lignocellulosic biofuels. Biotechnol. Bioeng. 109, 1083-1089.

Lark, N., Xia, Y.K., Qin, C.G., Gong, C.S., Tsao, G.T., 1997. Production of ethanol from recycled paper sludge using cellulase and yeast, Kluveromyces marxianus. Biomass Bioenergy 12, 135-143.

Lindedam, J., Haven, M., Chylenski, P., Jørgensen, H., Felby, C., 2013. Recycling cellulases for cellulosic ethanol production at industrial relevant conditions: potential and temperature dependency at high solid processes. Bioresour. Technol. 148, 180-188.
Lynd, L.R., Laser, M.S., Bransby, D., Dale, B.E., Davison, B., Hamilton, R., Himmel, M., Keller, M., McMillan, J.D., Sheehan, J., Wyman, C.E., 2008. How biotech can transform biofuels. Nat. Biotechnol. 26, 169-172.

Marques, S., Alves, L., Roseiro, J.C., Gírio, F.M., 2008a. Conversion of recycled paper sludge to ethanol by SHF and SSF using Pichia stipites. Biomass Bioenergy 32, 400-406.

Marques, S., Santos, J.A.L., Gírio, F.M., Roseiro, J.C., 2008b. Lactic acid production from recycled paper sludge by simultaneous saccharification and fermentation. Biochem. Eng. J. 41, 210-216.

Monte, M.C., Fuente, E., Blanco, A., Negro, C., 2009. Waste management from pulp and paper production in the European Union. Waste Manage. 29, 293-308.

Park, E.Y., Michinaka, A., Okuda, N., 2001. Enzymatic hydrolysis of waste office paper using viscosity as operating parameter. Biotechnol. Prog. 17, 379-382.

Pereira, F.B., Gomes, D.G., Guimarães, P.M.R., Teixeira, J.A., Domingues, L., 2012. Cell recycling during repeated very high gravity bio-ethanol fermentations using the industrial Saccharomyces cerevisiae strain PE-2. Biotechnol. Lett. 34, 45-53.

Pereira, F.B., Guimarães, P.M.R., Teixeira, J.A., Domingues, L., 2011. Robust industrial Saccharomyces cerevisiae strains for very high gravity bio-ethanol fermentations. J. Biosci. Bioeng. 112, 130-136.

Pereira, F.B., Guimarães, P.M.R., Teixeira, J.A., Domingues, L., 2010. Selection of Saccharomyces cerevisiae strains for efficient very high gravity bio-ethanol fermentation processes. Biotechnol. Lett. 32, 1655-1661.

Pereira, F.B., Romaní, A., Ruiz, H.A., Teixeira, J.A., Domingues, L., 2014. Industrial robust yeast isolates with great potential for fermentation of lignocellulosic biomass. Bioresour. Technol. 161, 192-199.

Presetyo, J., Park, E.Y., 2013. Waste paper sludge as a potential biomass for bioethanol production. Korean J. Chem. Eng. 30, 253-261.

Pribowo, A., Arantes, V., Saddler, J.N., 2012. The adsorption and enzyme activity profiles of specific Trichoderma reesei cellulose/xylanase components when hydrolyzing steam pretreated corn stover. Enzyme Microb. Technol. 50, 195203.

Rodrigues, A.C., Felby, C., Gama, M., 2014. Cellulase stability, adsorption/desorption profiles and recycling during successive cycles of hydrolysis and fermentation of wheat straw. Bioresour. Technol. 156, 163-169.

Rodrigues, A.C., Leitão, A.F., Moreira, S., Felby, C., Gama, M., 2012. Recycling of cellulases in lignocellulosic hydrolysates using alkaline elution. Bioresour. Technol. 110, 526-533.

Romani, A., Pereira, F., Johansson, B., Domingues, L., 2015. Metabolic engineering of Saccharomyces cerevisiae ethanol strains PE-2 and CAT-1 for efficient lignocellulosic fermentation. Bioresour. Technol. 179, 150-158.

Shang, Y., Su, R., Huang, R., Yang, Y., Qi, W., Li, Q., He, Z., 2014. Recycling cellulases by pH-triggered adsorption-desorption during the enzymatic hydrolysis of lignocellulosic biomass. Appl. Microbiol. Biotechnol. 98, 5765-5774.

Sun, Y., Cheng, J., 2002. Hydrolysis of lignocellulosic materials for ethanol production: a review. Bioresour. Technol. 83, 1-11.

Tu, M., Chandra, R.P., Saddler, J.N., 2007. Evaluating the distribution of cellulases and the recycling of free cellulases during the hydrolysis of lignocellulosic substrates. Biotechnol. Progr. 23, 398-406.

Zhu, Z., Sathitsuksanoh, N., Zhang, Y.-H.P., 2009. Direct quantitative determination of adsorbed cellulase on lignocellulosic biomass with its application to study cellulose desorption for potential recycling. Analyst 134, 2267-2272.

\section{Web references}

http://novozymes.com/en/news/news-archive/Pages/45713.aspx (last accessed in 15-04-2016).

http://www.nrel.gov/docs/fy13osti/59013.pdf (last accessed in 15-04-2016). 